\title{
A Study of the Cardiovascular Risk Factor Profile in Patients with Acute Coronary Syndrome with Particular Reference to Metabolic Syndrome
}

\author{
Mohammad Ali Sowdagar1, Adikesava Naidu Otikunta ${ }^{2 *}$, Y. V. Subba Reddy², \\ Chandra Sekhar Pulala1 \\ ${ }^{1}$ Department of Cardiology, Kurnool Medical College, Kurnool, India \\ ${ }^{2}$ Department of Cardiology, Osmania General Hospital and Osmania Medical College, Hyderabad, India \\ Email: "oadikesavanaidu@gmail.com
}

Received 26 October 2015; accepted 21 November 2015; published 24 November 2015

Copyright (C) 2015 by authors and Scientific Research Publishing Inc.

This work is licensed under the Creative Commons Attribution International License (CC BY). http://creativecommons.org/licenses/by/4.0/

(c) (i) Open Access

\section{Abstract}

Objectives: Cardiovascular risk factors for acute coronary syndrome (ACS) are on rise in people of Indian origin. Moreover, the prevalence of metabolic syndrome (MS) is higher in populations with ACS than in the general population. Thus, the aim of the study was to evaluate the cardiovascular risk factor profile of patients presenting with acute coronary syndrome and to study the prevalence and impact of metabolic syndrome in patients with acute coronary syndrome by using South Asian modified National cholesterol Education Program Adult Treatment Panel III definition. Methods: This study was conducted between October, 2010 and March, 2011 at Government General Hospital, Kurnool, India. A total of 100 patients with ST or non-ST segment elevation ACS and who had clinical, electrocardiographic and biochemical diagnosis within the first 24 hrs of clinical onset were enrolled in the study. The enrolled subjects were divided into two groups: those with MS and those without MS. Cardiovascular risk factors defined by components of MS were evaluated. Analysis was performed using SPSS software. Results: Sixty patients had MS along with ACS and 40 patients had ACS without MS. The most prevalent component of MS was increased waist circumference $(83.3 \%)$, followed by increased triglycerides $(\mathbf{7 8 . 3 \%})$ and increased fasting blood sugar (76.7\%). Majority of patients (58.3\%) had presence of three components of MS. Conclusion: The MS is a highly prevalent condition among the patients with ACS and is associated with severe coronary artery disease. The identification of MS imparts a high risk status to the patient in developing cardiovascular disease but at the same time provides abundant opportunities for intervention. Hence it is of paramount importance to aim for stricter goals and lower cut offs for intervention at all levels of prevention: primordial, primary and secondary.

\footnotetext{
${ }^{*}$ Corresponding author.
} 
Keywords

Acute Coronary Syndrome, Coronary Artery Disease, Metabolic Syndrome

\section{Introduction}

Asian Indians have one of the highest rates of coronary artery disease (CAD) worldwide. Over the past 30 years, the prevalence of CAD has amplified 300\% from $2 \%$ to $6 \%$ in rural India and from $4 \%$ to $12 \%$ in urban India [1]. Cardiovascular risk factors for acute coronary syndrome (ACS) are on rise in people of Indian origin, possess a high burden of CAD and are now an escalating cause of death [2].

Metabolic syndrome (MS) comprises of a miscellany of metabolic and hemodynamic disorders that elevate the development of atherosclerosis and upsurge cardiovascular morbidity and mortality [3]. The ultimate importance of this condition is that it helps to identify individuals at high risk of cardiovascular disease [4]. Thus, presence of MS along with ACS synergistically indicates the increased cardiovascular risk. The major characteristics of MS include insulin resistance, abdominal obesity, hypertension, and lipid abnormalities [i.e., elevated levels of triglycerides (TG) and low levels of high density lipoprotein (HDL)] [5]. The prevalence of MS is intensifying worldwide mostly due to obesity and sedentary lifestyles [6].

Every component of MS is autonomously coupled with an increased risk of cardiovascular disease. However, whether MS leads to greater cardiovascular risk than the sum of its components remains a subject of dispute [7]. It is reported that cardiovascular risk is directly proportional to the number of components of MS involved [8][10].

The prevalence of MS among patients with ACS varies between $29 \%$ and $46 \%$ and has been associated with poor in-hospital prognosis [11] [12]. Thus, this study aimed to evaluate the cardiovascular risk factor profile of patients presenting with acute coronary syndrome and to study the prevalence and impact of metabolic syndrome in patients with acute coronary syndrome by using South Asian modified National cholesterol Education Program Adult Treatment Panel III (NCEP-ATP III) definition.

\section{Patients and Methods}

This single-centric, observational study was conducted at Government General Hospital, Kurnool, India. A total of 100 patients with acute coronary syndrome were enrolled between October, 2010 and March, 2011. The study subjects were divided into two groups: those with metabolic syndrome and those without metabolic syndrome. The presence of metabolic syndrome and its components was determined by applying Adult Treatment Panel III criteria. The NCEP-ATP III definition [13] of the MS is based on vital clinical and biochemical parameters, but it does not identify the MS optimally in South Asians [14]. Thus, we considered South Asian modified NCEPATP III definition for MS in this study. The study was conducted in accordance with the Declaration of Helsinki and country-specific regulatory requirements. All patients signed informed consent form which was reviewed and approved by the Institutional Review Board (Ethics Committee).

The patients were included if diagnosed with ST (ST wave segment in ECG) or non-ST segment elevation acute coronary syndrome (ACS) and who had clinical, electrocardiographic and biochemical diagnosis within the first $24 \mathrm{~h}$ of clinical onset; patients with unstable angina; patients more than 18 years of age. Patients with hypertension, diabetes and obesity on drug therapy were also included in the study.

Patients were excluded if found to have disease other than acute coronary syndrome on evaluation. Seriously ill patients, patients with acute infection, neoplastic disease, cardiomyopathies, cardiogenic shock at admission; patients with other major organ (liver, kidney, brain) chronic illness or degenerative disease with life expectancy $<2$ years; patients on drugs, unrelated to lipid lowering therapy \& known to alter serum lipid profile (long term steroids, diuretics, other proprietary medications, etc.) were excluded from the study.

\subsection{Study Procedure}

All the patients were subjected to detailed history and complete physical examination and the data collected was recorded in a predesigned proforma. All patients underwent diagnosis of ACS as per American College of Car- 
diology and American Heart Association (ACC/AHA) criteria, waist circumference as per national health and nutrition survey study, blood and urine routine investigations, fasting blood sugar, $12 \mathrm{hr}$ fasting lipid profile, 12 lead ECG, 2 D echocardiography, coronary angiography, and evaluation of metabolic syndrome using South Asian modified NCEP-ATP III criteria. The cardiovascular risk factor profile was studied with particular reference to metabolic syndrome and the results were statistically analysed.

\subsection{Definition of Terms}

Patients with ACS were defined according to criteria established by the ACC/AHA through evaluation of myocardial necrosis markers in serial determinations [MB fraction of creatine phosphokinase (CPK) $\geq 10 \%$ of total $\mathrm{CPK}$ and/or troponin-I (TNI) $\geq 1 \mathrm{ng} / \mathrm{ml}]$ plus one of the following criteria: precordial ischemic pain $>30 \mathrm{~min}$ with or without dyspnea; diaphoresis, nausea and/or vomiting; ST-segment elevation in electro-cardiogram $>1$ $\mathrm{mm}$ in two or more contiguous leads; pathologic Q wave or left bundle branch block, new or presumed new [15].

National cholesterol Education Program Adult Treatment Panel III (NCEP-ATP III) definition of metabolic syndrome, as per south Asian modifications [14], includes three or more of the following: central obesity (waist circumference): $>90 \mathrm{~cm}$ (male) or $>80 \mathrm{~cm}$ (female); triglycerides: $>150 \mathrm{mg} \%$; HDL cholesterol: $<40$ $\mathrm{mg} \%$ (male) or $<50 \mathrm{mg} \%$ (female); hypertension (blood pressure): >130/85 mmHg; fasting plasma glucose: >100 $\mathrm{mg} \%$.

\subsection{Statistical Analysis}

Continuous variables are expressed as mean \pm standard deviation, and categorical variables as absolute and relative frequencies. Quantitative data were analysed using the Student t-test to compare means. Dichotomous variables were tested using $\chi^{2}$ test or Fisher's exact test according to expected frequencies. A p value of $<0.05$ was considered statistically significant. Statistical analysis was performed with the use of Statistical Package for Social Sciences (SPSS; Chicago, IL, USA) program, version 15.

\section{Results}

A total of 100 patients with ACS were enrolled in the study. Sixty patients had MS along with ACS (Group 1) and 40 patients had ACS without MS (Group 2). The clinical characteristics of the patients are outlined in Table 1. The mean age was 52.1 and 48.9 years in Group 1 and Group 2, respectively; male gender represented 49 (56.3\%) and 38 (43.7\%) patients in Group 1 and 2, respectively. Histories of hypertension, coronary artery disease and diabetes were more prevalent in patients with MS. The most prevalent clinical presentation was unstable angina in patients with MS and myocardial infarction in patients without MS. All the components of MS varied significantly between the two groups. The most prevalent component of MS was increased waist circumference, followed by increased triglycerides and increased fasting blood sugar. The clinical characteristics of patients categorised according to gender are detailed in Table 2.

Various modalities approached for the treatment of ACS are outlined in Table 3. The most applied modality was treatment through medication, followed by percutaneous coronary intervention and coronary artery bypass surgery. In Group 1, 23 (38.3\%) patients and in Group 2, 24 (60\%) patients were treated medically.

Figure 1 depicts the number of patients in correspondence to presence of number of components of MS. In males, three MS components were most prevalent. Whereas, in females, four components of MS were most prevalent. Overall, majority of patients (58.3\%) had MS with three components.

\section{Discussion}

The prevalence of MS is higher in populations with ACS than in the general population; this demonstrates an association between MS and ischemic heart disease [16]. Though the exact mechanism by which components of MS convenes an increased risk of cardiovascular disease in the setting of ACS is not absolutely known, several hypotheses have been proposed. Components of MS enhance proinflammatory and prothrombotic [6] [17] mechanisms by increasing cytokines production, such as C-reactive protein and interleukin-6, ultimately resulting in endothelial dysfunction [18].

In present study, patients with ACS were examined for the presence of MS by using NCEP-ATP III criteria. 
Table 1. Clinical characteristics of patients.

\begin{tabular}{|c|c|c|c|}
\hline Characteristics & $\begin{array}{l}\text { With metabolic syndrome } \\
\qquad(\mathbf{N}=\mathbf{6 0})\end{array}$ & $\begin{array}{l}\text { Without metabolic } \\
\text { syndrome }(N=40)\end{array}$ & p value \\
\hline Age, (mean, yrs) & 52.1 & 48.9 & 0.75 \\
\hline \multicolumn{4}{|c|}{ Gender } \\
\hline Male, n (\%) & 49 (56.3\%) & $38(43.7 \%)$ & \multirow{2}{*}{0.10} \\
\hline Female, n (\%) & $11(84.6 \%)$ & $2(15.4 \%)$ & \\
\hline Smoking, n (\%) & $14(23.3 \%)$ & $14(35 \%)$ & 0.30 \\
\hline History of hypertension, n (\%) & $30(50.0 \%)$ & $12(30.0 \%)$ & 0.05 \\
\hline History of diabetes mellitus, n (\%) & 19 (31.7\%) & $7(17.5 \%)$ & 0.18 \\
\hline Obesity, n (\%) & $14(23.3 \%)$ & $6(15 \%)$ & 0.44 \\
\hline History of coronary artery disease, $n$ (\%) & $10(16.7 \%)$ & $5(12.5 \%)$ & 0.78 \\
\hline Increased total cholesterol, n (\%) & $52(86.7 \%)$ & 27 (67.5\%) & 0.04 \\
\hline Increased non-HDL, n (\%) & $40(66.7 \%)$ & $18(45 \%)$ & 0.03 \\
\hline Increased low density lipoprotein, n (\%) & $21(35.0 \%)$ & $10(25.0 \%)$ & 0.40 \\
\hline Increased total cholesterol/HDL ratio, n (\%) & $6(10.0 \%)$ & $5(12.5 \%)$ & 0.95 \\
\hline Left ventricle dysfunction, $\mathrm{n}(\%)$ & $40(66.7 \%)$ & $31(77.5 \%)$ & 0.34 \\
\hline Myocardial infarction, n (\%) & $24(40 \%)$ & $23(57.5 \%)$ & \multirow{2}{*}{$>0.05$} \\
\hline Unstable angina, $\mathrm{n}(\%)$ & $36(60 \%)$ & 17 (42.5\%) & \\
\hline Abnormal CAG, n (\%) & $46(76.7 \%)$ & $26(65.0 \%)$ & 0.29 \\
\hline Single vessel disease, $\mathrm{n}(\%)$ & $16(26.7 \%)$ & 13 (32.5\%) & \multirow{3}{*}{0.56} \\
\hline Double vessel disease, n (\%) & $15(25.0 \%)$ & $8(20.0 \%)$ & \\
\hline Triple vessel disease, n (\%) & $15(25.0 \%)$ & $5(12.5 \%)$ & \\
\hline \multicolumn{4}{|c|}{ Components of metabolic syndrome } \\
\hline Increased waist circumference, $\mathrm{n}(\%)$ & $50(83.3 \%)$ & $18(45 \%)$ & 0.0001 \\
\hline Hypertension, n (\%) & $42(70.0 \%)$ & $5(12.5 \%)$ & $\leq 0.001$ \\
\hline High fasting blood sugar, n (\%) & $46(76.7 \%)$ & $18(45.0 \%)$ & 0.0025 \\
\hline Decreased HDL, n (\%) & $22(36.7 \%)$ & $8(20.0 \%)$ & 0.03 \\
\hline Increased triglycerides, n (\%) & 47 (78.3\%) & $21(52.5 \%)$ & 0.01 \\
\hline
\end{tabular}

HDL—High density lipoprotein; CAG—Coronary angiography.

Prevalence of MS was found to be $60 \%$ in the study population. Waist circumference, hypertension, TG, HDL, and fasting blood sugar were the included components of MS. Factors that were associated with MS were increased total cholesterol, non-HDL components and low density lipoproteins; histories of hypertension, diabetes, and CAD; obesity; and female gender. Although the prevalence of MS is greater in men than in women in the general population [19], our study suggests that MS is more prevalent in women than in men ( $84.6 \%$ vs. $56.3 \%)$, which is similar to the results obtained in other populations with ischemic heart disease [20]-[22]. The most prevalent component of MS was increased waist circumference (83.3\%), followed by increased triglycerides (78.3\%) and increased fasting blood sugar (76.7\%). The patients without MS were majorly treated with medications (60\%), which suggest that the condition of such patients might have been comparatively less severe than patients with MS, such that they did not require an intervention.

In previous studies, hyperglycemia and low HDL levels were the most prevalent components of MS, followed by hypertension [16] [23]. Some studies have depicted that the combination of diabetes and hypertension sharply increases cardiovascular risk [24]. 
Table 2. Clinical characteristics of patients with metabolic syndrome as per gender.

\begin{tabular}{|c|c|c|c|}
\hline Characteristics & Males $(n=49)$ & Females $(n=11)$ & p value \\
\hline Smoking, n (\%) & $14(23.3 \%)$ & $0(0 \%)$ & $>0.05$ \\
\hline History of hypertension, n (\%) & $22(44.9 \%)$ & $8(72.7 \%)$ & 0.19 \\
\hline History of diabetes mellitus, $\mathrm{n}(\%)$ & $15(30.6 \%)$ & $4(36.4 \%)$ & 0.60 \\
\hline Obesity, n (\%) & $9(18.4 \%)$ & $5(45.5 \%)$ & 0.39 \\
\hline History of coronary artery disease, $n(\%)$ & $8(16.3 \%)$ & $2(18.2)$ & 0.49 \\
\hline Increased total cholesterol, n (\%) & $42(85.7 \%)$ & $10(90.9 \%)$ & 0.69 \\
\hline Increased non-HDL, n (\%) & $32(65.3 \%)$ & $8(72.7 \%)$ & 0.63 \\
\hline Increased low density lipoprotein, n (\%) & $19(38.8 \%)$ & $2(18.2 \%)$ & 0.19 \\
\hline Increased total cholesterol/HDL ratio, n (\%) & $5(10.2 \%)$ & $1(9.1 \%)$ & $>0.05$ \\
\hline Left ventricle dysfunction, n (\%) & $34(69.4 \%)$ & $6(54.5 \%)$ & $>0.05$ \\
\hline Abnormal CAG, n (\%) & $40(66.7 \%)$ & $6(54.5 \%)$ & $>0.05$ \\
\hline \multicolumn{4}{|c|}{ Components of metabolic syndrome } \\
\hline Increased waist circumference, $\mathrm{n}(\%)$ & $44(89.8 \%)$ & $6(54.5 \%)$ & 0.24 \\
\hline Hypertension, n (\%) & $34(69.4 \%)$ & $8(72.7 \%)$ & 0.60 \\
\hline High fasting blood sugar, n (\%) & $37(75.5 \%)$ & $9(81.8 \%)$ & 0.56 \\
\hline Increased triglycerides, n (\%) & 38 (77.6\%) & $9(81.8 \%)$ & 0.034 \\
\hline Decreased HDL, n (\%) & $11(22.4 \%)$ & $11(100 \%)$ & $<0.001$ \\
\hline
\end{tabular}

HDL—High density lipoprotein; CAG—Coronary angiography.

Table 3. Treatment modalities in patients with acute coronary syndrome.

\begin{tabular}{ccc}
\hline Treatments & $\begin{array}{c}\text { With } \\
\text { metabolic syndrome (N = 60) }\end{array}$ & $\begin{array}{c}\text { Without metabolic syndrome } \\
\mathbf{( N = 4 0 )}\end{array}$ \\
\hline Percutaneous coronary intervention, n (\%) & $17(28.3 \%)$ & $11(27.5 \%)$ \\
Aortic valve replacement, n (\%) & $1(1.7 \%)$ & $0(0 \%)$ \\
Coronary artery bypass surgery, n (\%) & $18(30.0 \%)$ & $5(12.5 \%)$ \\
Temporary pacemaker, n (\%) & $1(1.7 \%)$ & $0(0 \%)$ \\
Medications, n (\%) & $23(38.3 \%)$ & $24(60.0 \%)$ \\
\hline
\end{tabular}

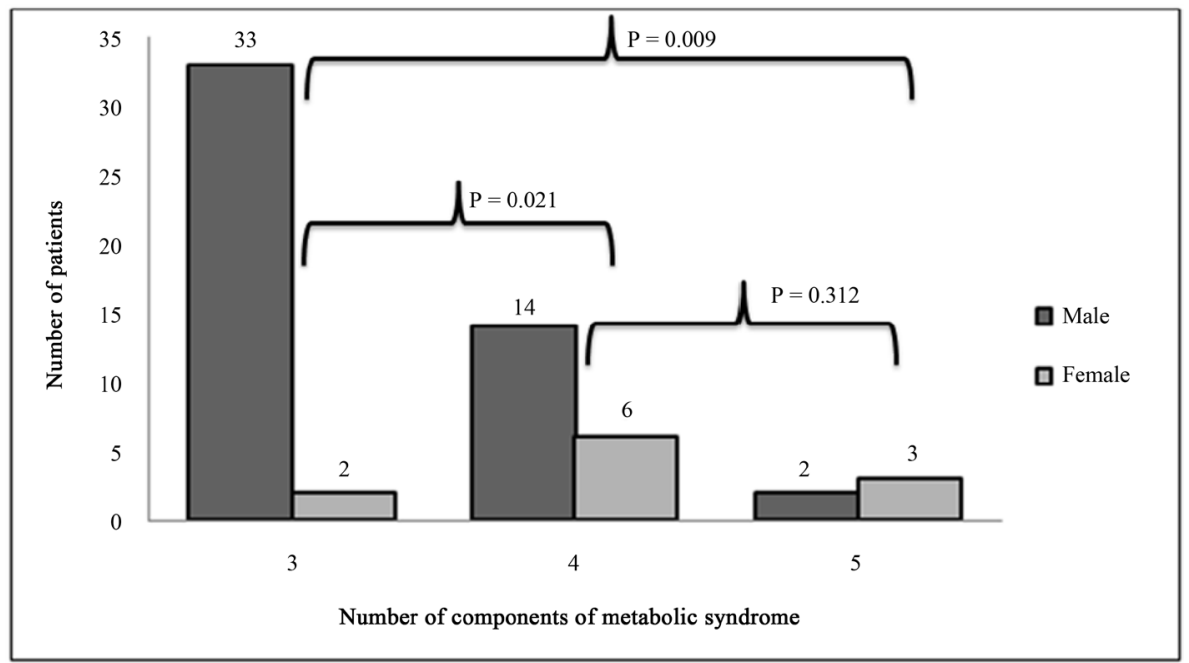

Figure 1. Number of patients in correspondence to presence of number of components of metabolic syndrome. 
A recent community-based study from Eastern India had measured a prevalence of MS of $31.4 \%$, with females having a much higher prevalence (48.2\%) than males (16.3\%) [25]. In rural areas of Central India [26], the prevalence of MS was 9.3\% as per modified ATP criteria and in semi-urban parts of South India [27], MS was found in $29.7 \%$ of population. In another South Indian study, the prevalence of MS was estimated to be 23.2\% as per NCEP-ATP III definition [28].

A previous study in Oman [29] reported 66\% prevalence and another study in Spain reported 50.9\% prevalence of MS among patients with ACS [16]. The data proposes that presence of MS in patients of ACS is higher than in patients without ACS. Furthermore, a study in Nepal which employed NCEP-ATP III criteria in patients of ACS with MS, reported the presence of MS to be $57.4 \%$ and MS with three components was documented in $62.5 \%$ patients [30]. The results of this study are similar to the present study, indicating an increased prevalence of MS in Asians.

Moreover, Asian Indians are in dual jeopardy of bearing the genetically-determined excess of insulin resistance, diabetes and lipoprotein- $\mathrm{A}$, and possessing an ever-increasing unhealthy lifestyle associated with rising affluence, urbanization, and mechanization [31]. Further, the patients with ACS represent a cohort with addition of multiple risk factors that have ended up with adverse coronary events.

\section{Study Strengths and Limitations}

The study adds to the literature, the prevalence of MS in patients with ACS in a particular region of India with detailed clinical characteristics of population. The study holds the limitation of a small sample size and single-centered study. More accurate presentation of prevalence of MS could be possible by using multiple criteria in the same set of population.

\section{Conclusion}

The metabolic syndrome is a highly prevalent condition among the patients with acute coronary syndrome and is associated with severe CAD. Metabolic syndrome is a clustering of risk factors of metabolic origin that are together associated with higher risk of cardiovascular disease and hence the need to develop strategies with multipronged intervention for controlling this syndrome and its component conditions. The identification of metabolic syndrome imparts a high risk status to the patient in developing cardiovascular disease but at the same time provides abundant opportunities for intervention. Hence it is of paramount importance to aim for stricter goals and lower cut offs for intervention at all levels of prevention: primordial, primary and secondary.

\section{References}

[1] Zargar, A.H. (2015) Type 1 Diabetes Guidelines: Are They Enough? Indian Journal of Endocrinology and Metabolism, 19, S18. http://dx.doi.org/10.4103/2230-8210.155355

[2] Yadav, P., Joseph, D., Joshi, P., Sakhi, P., Jha, R. and Gupta, J. (2010) Clinical Profile \& Risk Factors in Acute Coronary Syndrome. National Journal of Community Medicine, 1, 150-151.

[3] Boulon, C., Lafitte, M., Richeboeuf, V., Paviot, B., Pradeau, V., Coste, P., et al. (2006) Prevalence of Metabolic Syndrome after Acute Coronary Syndrome and Its Prognostic Significance. The American Journal of Cardiology, 98, 1429-1434. http://dx.doi.org/10.1016/j.amjcard.2006.07.025

[4] Deedwania, P. and Gupta, R. (2006) Management Issues in the Metabolic Syndrome. JAPI, 54, 797-810.

[5] Munjal, Y. and Sarena, A. (2007) Metabolic Syndrome: Assessing Cardiometabolic Risk. JP Publishers.

[6] Grundy, S.M., Hansen, B., Smith, S.C., Cleeman, J.I. and Kahn, R.A. (2004) Clinical Management of Metabolic Syndrome Report of the American Heart Association/National Heart, Lung, and Blood Institute/American Diabetes Association Conference on Scientific Issues Related to Management. Circulation, 109, 551-556. http://dx.doi.org/10.1161/01.CIR.0000112379.88385.67

[7] Mente, A., Yusuf, S., Islam, S., McQueen, M.J., Tanomsup, S., Onen, C.L., et al. (2010) Metabolic Syndrome and Risk of Acute Myocardial Infarction: A Case-Control Study of 26,903 Subjects from 52 Countries. Journal of the American College of Cardiology, 55, 2390-2398. http://dx.doi.org/10.1016/j.jacc.2009.12.053

[8] Lakka, H.-M., Laaksonen, D.E., Lakka, T.A., Niskanen, L.K., Kumpusalo, E., Tuomilehto, J., et al. (2002) The Metabolic Syndrome and Total and Cardiovascular Disease Mortality in Middle-Aged Men. JAMA, 288, 2709-2716. http://dx.doi.org/10.1001/jama.288.21.2709

[9] Sattar, N., Gaw, A., Scherbakova, O., Ford, I., O’Reilly, D.S.J., Haffner, S.M., et al. (2003) Metabolic Syndrome with 
and without C-Reactive Protein as a Predictor of Coronary Heart Disease and Diabetes in the West of Scotland Coronary Prevention Study. Circulation, 108, 414-419. http://dx.doi.org/10.1161/01.CIR.0000080897.52664.94

[10] Malik, S., Wong, N.D., Franklin, S.S., Kamath, T.V., Gilbert, J., Pio, J.R., et al. (2004) Impact of the Metabolic Syndrome on Mortality from Coronary Heart Disease, Cardiovascular Disease, and all Causes in United States Adults. Circulation, 110, 1245-1250. http://dx.doi.org/10.1161/01.CIR.0000140677.20606.0E

[11] Schwartz, G.G., Olsson, A.G., Szarek, M. and Sasiela, W.J. (2005) Relation of Characteristics of Metabolic Syndrome to Short-Term Prognosis and Effects of Intensive Statin Therapy after Acute Coronary Syndrome an Analysis of the Myocardial Ischemia Reduction with Aggressive Cholesterol Lowering (MIRACL) Trial. Diabetes Care, 28, 25082513. http://dx.doi.org/10.2337/diacare.28.10.2508

[12] Feinberg, M.S., Schwartz, R., Tanne, D., Fisman, E.Z., Hod, H., Zahger, D., et al. (2007) Impact of the Metabolic Syndrome on the Clinical Outcomes of Non-Clinically Diagnosed Diabetic Patients with Acute Coronary Syndrome. The American Journal of Cardiology, 99, 667-672. http://dx.doi.org/10.1016/j.amjcard.2006.10.023

[13] National Cholesterol Education Program, National Heart, Lung and Blood Institute (2001) Executive Summary of the Third Report of the National Cholesterol Education Program (NCEP) Expert Panel on Detection, Evaluation, and Treatment of High Blood cholesterol in Adults (Adult Treatment Panel III). JAMA, 285, 2486-2897. http://dx.doi.org/10.1001/jama.285.19.2486

[14] Misra, A., Misra, R., Wijesuriya, M. and Banerjee, D. (2007) The Metabolic Syndrome in South Asians: Continuing Escalation \& Possible Solutions. Indian Journal of Medical Research, 125, 345-354.

[15] Cannon, C.P., Battler, A., Brindis, R.G., Cox, J.L., Ellis, S.G., Every, N.R., et al. (2001) American College of Cardiology Key Data Elements and Definitions for Measuring the Clinical Management and Outcomes of Patients with Acute Coronary Syndromes: A Report of the American College of Cardiology Task Force on Clinical Data Standards (Acute Coronary Syndromes Writing Committee) Endorsed by the American Association of Cardiovascular and Pulmonary Rehabilitation, American College of Emergency Physicians, American Heart Association, Cardiac Society of Australia \& New Zealand, National Heart Foundation of Australia, Society for Cardiac Angiography and Interventions, and the Taiwan Society of Cardiology. Journal of the American College of Cardiology, 38, 2114-2130. http://dx.doi.org/10.1016/S0735-1097(01)01702-8

[16] Jover, A., Corbella, E., Muñoz, A., Millán, J., Pintó, X., Mangas, A., et al. (2011) Prevalence of Metabolic Syndrome and Its Components in Patients with Acute Coronary Syndrome. Revista Española de Cardiología (English Edition), 64, 579-586. http://dx.doi.org/10.1016/j.rec.2011.03.009

[17] Solymoss, B.C., Bourassa, M.G., Campeau, L., Sniderman, A., Marcil, M., Lespérance, J., et al. (2004) Effect of Increasing Metabolic Syndrome Score on Atherosclerotic Risk Profile and Coronary Artery Disease Angiographic Severity. The American Journal of Cardiology, 93, 159-164. http://dx.doi.org/10.1016/j.amjcard.2003.09.032

[18] Pilz, S., Scharnagl, H., Tiran, B., Seelhorst, U., Wellnitz, B., Boehm, B.O., et al. (2006) Free Fatty Acids Are Independently Associated with All-Cause and Cardiovascular Mortality in Subjects with Coronary Artery Disease. The Journal of Clinical Endocrinology \& Metabolism, 91, 2542-2547. http://dx.doi.org/10.1210/jc.2006-0195

[19] Nakatani, D., Sakata, Y., Sato, H., Mizuno, H., Shimizu, M., Suna, S., et al. (2007) Clinical Impact of Metabolic Syndrome and Its Additive Effect with Smoking on Subsequent Cardiac Events after Acute Myocardial Infarction. The American Journal of Cardiology, 99, 885-889. http://dx.doi.org/10.1016/j.amjcard.2006.11.033

[20] Zaliūnas, R., Slapikas, R., Babarskiene, R., Slapikiene, B., Luksiene, D., Milvidaite, I., et al. (2007) The Prevalence of the Metabolic Syndrome Components and Their Combinations in Men and Women with Acute Ischemic Syndromes. Medicina, 44, 521-528.

[21] Anand, S.S., Islam, S., Rosengren, A., Franzosi, M.G., Steyn, K., Yusufali, A.H., et al. (2008) Risk Factors for Myocardial Infarction in Women and Men: Insights from the INTERHEART Study. European Heart Journal, 29, 932-940. http://dx.doi.org/10.1093/eurheartj/ehn018

[22] BirhanYilmaz, M., Guray, U., Guray, Y., Altay, H., Demirkan, B., Caldir, V., et al. (2005) Metabolic Syndrome Is Associated with Extension of Coronary Artery Disease in Patients with Non-ST Segment Elevation Acute Coronary Syndromes. Coronary Artery Disease, 16, 287-292. http://dx.doi.org/10.1097/00019501-200508000-00005

[23] Levantesi, G., Macchia, A., Marfisi, R., Franzosi, M.G., Maggioni, A.P., Nicolosi, G.L., et al. (2005) Metabolic Syndrome and Risk of Cardiovascular Events after Myocardial Infarction. Journal of the American College of Cardiology, 46, 277-283. http://dx.doi.org/10.1016/j.jacc.2005.03.062

[24] Stamler, J., Vaccaro, O., Neaton, J.D. and Wentworth, D. (1993) Diabetes, Other Risk Factors, and 12-Yr Cardiovascular Mortality for Men Screened in the Multiple Risk Factor Intervention Trial. Diabetes Care, 16, 434-444. http://dx.doi.org/10.2337/diacare.16.2.434

[25] Das, M., Pal, S. and Ghosh, A. (2010) Association of Metabolic Syndrome with Obesity Measures, Metabolic Profiles, and Intake of Dietary Fatty Acids in People of Asian Indian Origin. Journal of Cardiovascular Disease Research, 1, 130-135. http://dx.doi.org/10.4103/0975-3583.70911 
[26] Kamble, P., Deshmukh, P.R. and Garg, N. (2010) Metabolic Syndrome in Adult Population of Rural Wardha, Central India. The Indian Journal of Medical Research, 132, 701-705.

[27] Pemminati, S., Adhikari, P.M., Pathak, R. and Pai, M. (2010) Prevalence of Metabolic Syndrome (METS) Using IDF 2005 Guidelines in a Semi Urban South Indian (Boloor Diabetes Study) Population of Mangalore. Journal of Association Physicians of India, 58, 674-677.

[28] Deepa, M., Farooq, S., Datta, M., Deepa, R. and Mohan, V. (2007) Prevalence of Metabolic Syndrome Using WHO, ATPIII and IDF Definitions in Asian Indians: The Chennai Urban Rural Epidemiology Study (CURES-34). Diabetes/Metabolism Research and Reviews, 23, 127-134. http://dx.doi.org/10.1002/dmrr.658

[29] Al-Rasadi, K., Sulaiman, K., Panduranga, P. and Al-Zakwani, I. (2011) Prevalence, Characteristics, and In-Hospital Outcomes of Metabolic Syndrome among Acute Coronary Syndrome Patients from Oman. Angiology, 62, 381-389. http://dx.doi.org/10.1177/0003319710382419

[30] Rajbhandari, A., Pandeya, D.R., Bhattarai, M.D., Malla, R., Sharma, A., Shrestha, D., et al. (2015) Prevalence of Metabolic Syndrome and Its Component in Patients with Acute Coronary Syndrome. Medical Journal of Shree Birendra Hospital, 12, 42-48. http://dx.doi.org/10.3126/mjsbh.v12i2.12928

[31] Enas, E.A., Chacko, V., Pazhoor, S.G., Chennikkara, H. and Devarapalli, H.P. (2007) Dyslipidemia in South Asian Patients. Current Atherosclerosis Reports, 9, 367-374. http://dx.doi.org/10.1007/s11883-007-0047-y 